\title{
The influence of ferrihydrite nanoparticles on induction and proliferation of Triticum aestivum mature embryo callus culture
}

Stupko V.Yu. ${ }^{1}$, Zobova N.V. ${ }^{1}$, Gurevich Yu.L. ${ }^{2}$

${ }^{1}$ Krasnoyarsk Agricultural Research Institute, Federal Research Center "Krasnoyarsk Scientific Center of the SB of the RAS", Krasnoyarsk, Russia; ${ }^{2}$ Federal Research Center "Krasnoyarsk Scientific Center of the SB of the RAS”, Krasnoyarsk, Russian Federation, Krasnoyarsk, Russia E-mail: stupko@list.ru

Key message. The presence of biogenic ferrihydrite nanoparticles at callusogenesis stage decreases the level of necrosis at proliferation stage. Ferrihydrite doesn't influence on callus growth at the second stage, but decreases the percentage of samples with chlorophyll.

Keywords: wheat, callus culture, nanoparticles, ferrihydrite

Biogenic ferrigydrite (FH) possesses a high catalytic activity for hydrogen peroxide decomposition. Thus, it can influence on the level of active oxygen forms in plant cells and, thereafter, - on their growth and development. The identification of probable points of FH influence on plant cells, using wheat callus culture (CC) as a suitable model system, was the aim of present study.

Callusogenesis was induced in mature embryo culture at Murashige-Skoog media with 2mg/l 2.4-D (control (ICnt)), involving wheat genotypes selected by KrasARI. The experimental media contained 1 (IF1) and 10 (IF10) mg/l of FH. After 1-month calluses $(n=50)$ were moved to proliferation media $(P)$ of the same salt and hormonal composition: to PF1 and PCnt in equal quantities. The callus size, the presence of chlorophyll-containing areas (ChCA) at all stages and the necrosis signs on $30^{\text {th }}$ and $44^{\text {th }}$ day of cultivation on proliferation media were registered.

The influence of genotype on the callus size at the first stage was confirmed $\left(\eta^{2}=0.22, p<0.01\right)$. Concentration of FH up to 10 $\mathrm{mg} / \mathrm{l}$ decreased the callus size $(\mathrm{p}<0.05)$. While the $1 \mathrm{mg} / \mathrm{l}$ of $\mathrm{FH}$ didn`t results in any changes in culture growth.

The percentage of calluses with necrosis at $30^{\text {th }}$ day in CC, moved from IF1, was higher on PF1 media (43.5\%) than on PCnt one $(27.9 \%, \mathrm{p}=0.04)$. There was no such difference in $\mathrm{CC}$, moved from ICnt. But the level of ChCA decreased twice under these conditions (PF1) compared to the data, recorded on PCnt ( $\mathrm{p}=0.01)$, no mater of callusogenesis induction media composition.

The influence of FH level in induction media on further percentage of sample with necrosis on second stage was marked $46.2 \%, 35.7 \%$ and $24.5 \%$ for CC, moved from ICnt, IF1 and IF10 media, respectively $\left(\chi^{2}=5.89, \mathrm{p}=0.05\right)$.

Thus, in spite of the fact, that FH introduction into the medium in high concentration of $10 \mathrm{mg} / \mathrm{l}$ resulted in decrease of inducted callus linear growth, the $\mathrm{CC}$, that had developed on such medium, maintained viability much longer. The influence of FH on CC proliferation, that expressed in ChCA percentage decrease and necrotizing calluses level increase, indicates the toxicity of this chemical agent in the present concentration. So, the further investigation of FH lower concentrations influence on $\mathrm{CC}$ parameters is required.

\section{Влияние наночастиц ферригидрита на индукцию и пролиферацию каллусных культур зрелых зародышей Triticum aestivum Ступко В.Ю. ${ }^{1}$, Зобова Н.В. ${ }^{1}$, Гуревич Ю.Л. ${ }^{2}$ \\ ${ }^{1}$ Красноярский научно-исследовательский институт сельского хозяйства, ФИЦ «Красноярский научный центр СО РАН»,}

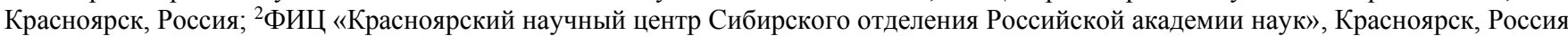

\footnotetext{
Аннотация. Присутствие наночастии биогенного ферригидрита на этапе каллусогенеза снижает уровень некроза на среде пролиферации. Ферригидрит не влияет на рост каллусов на втором этапе, но уменьшает долю хлорофиллсодержсащих образцов. Ключевые слова: пшеница, каллусные культуры, наночастищы, ферригидрит

Биогенный ферригидрит (ФГ) обладает высокой каталитической активностью при разложении пероксида водорода, что может влиять на уровень активных форм кислорода в растительных клетках и, соответственно, - на их рост и развитие. Выявление возможных сайтов воздействия ФГ на растительные клетки с использованием каллусных культур (КК) пшеницы, как удобного модельного объекта, являлось целью настоящей работы.

Каллусогенез индуцировали в культуре зрелых зародышей пшеницы генотипов селекции КрасНИИСХ на среде Мурасиге-Скуга с добавлением 2 мг/л 2,4-Д (контрольный вариант (ICnt)). Опытная среда содержала 1 (IF1) или 10 (IF10) мг/л ФГ. Спустя 1 месяц каллусы $(\mathrm{n}=50)$ пассировали на среду пролиферации того же солевого и гормонального состава: на PF1 и PCnt в paвных количествах. Фиксировали размер каллусов, наличие хлорофилл-содержащих областей (XСО) на всех этапах, проявление некроза на 30 -е и 44-е сутки на среде пролиферации.

На первом этапе культивирования показано влияние генотипа на размер формируемого каллуса $\left(\eta^{2}=0,22, p<0,01\right)$. Добавление в среду 10 мг/л ФГ снижало размер каллуса $(\mathrm{p}<0,05)$, в то время как 1 мг/л ФГ не оказывал эффекта.

На 30-е сутки после пассирования со среды IF1 отмечена бо́льшая доля некроза на среде пролиферации с ФГ - 43,5\%, против $27,9 \%$ на PCnt среде $(\mathrm{p}=0,04)$. У каллусов со среды ICnt такого эффекта не отмечалось. Наличие ФГ в среде пролиферации не влияло на рост КК. Однако, в этих условиях (PF1), уровень ХСО снижался в 2 раза по сравнению с данными, полученными на среде PCnt $(\mathrm{p}=0,01)$, независимо от состава среды индукции каллусогенеза.

На 44-е сутки культивирования на средах пролиферации отмечено влияние уровня ФГ в среде индукции на долю некротизированных каллусов на втором этапе, 46,2\%, 35,7\% и 24,5\% - для каллусов, пассированных с ICnt, IF1 и IF10 сред, соответственно $\left(\chi^{2}=5,89, \mathrm{p}=0,05\right)$.

Таким образом, несмотря на то, что внесение ФГ в среду индукции в высокой концентрации 10 мг/л приводило к снижению активного роста индуцированных каллусов, ткани, полученные на данной среде, впоследствии дольше сохраняли свою жизнеспособность. Влияние ФГ на пролиферацию КК, выразившееся в снижении доли ХСО и увеличении доли некроза говорит о токсичности данного агента в заданной концентрации и требует дальнейших исследований в отношении воздействия меньших концентраций на параметры КК.
} 